\title{
The relationship between childhood trauma and alcohol use initiation in Black and White adolescent girls: considering socioeconomic status and neighborhood factors
}

\author{
Carolyn E. Sartor ${ }^{a},{ }^{\dagger}$, Rachel L. Bachrach ${ }^{b}$, Stephanie D. Stepp ${ }^{b}$, Kimberly B. Werner ${ }^{c}$, \\ Alison E. Hipwell ${ }^{b}$, and Tammy Chung ${ }^{b}$ \\ aDepartment of Psychiatry, Yale University School of Medicine, 389 Whitney Avenue, New Haven, \\ CT, 06511, USA \\ bDepartment of Psychiatry, University of Pittsburgh, Pittsburgh, PA 15213, USA \\ cMissouri Institute of Mental Health, University of Missouri - St. Louis, St. Louis, MO, USA
}

\begin{abstract}
Purpose-To assess whether the higher prevalence of childhood trauma exposure but lower prevalence of alcohol use in Black vs. White adolescent girls reflects a lower magnitude of association between trauma and alcohol use initiation in Black vs. White girls; and additionally, whether low socioeconomic status (SES) and neighborhood factors account in part for the link between trauma and early alcohol use.
\end{abstract}

Methods-Data were drawn from annual interviews conducted with an urban sample of girls and their primary caregivers from ages 5-8 (baseline) through age 17 ( $n=2,068,57.7 \%$ Black, 42.3\% White). Cox proportional hazards regression analyses using race and childhood trauma to predict alcohol use initiation were conducted in two stages, with SES and neighborhood factors added in the second stage.

Results-Childhood trauma was more prevalent (29.0\% vs. $17.5 \%)$ and alcohol use initiation less prevalent (37.7\% vs. 54.4\%) in Black vs. White girls, but we found no evidence for differences in liability conferred by trauma. However, significant changes in hazards ratios (HRs) from the unadjusted to adjusted models were observed for Black race (HR $=0.57, \mathrm{CI}: 0.50-0.65$ to $\mathrm{HR}=0.66$, CI:0.54-0.80) and childhood trauma (HR=1.70, CI:1.46-1.99 to HR=1.34, CI:1.05$1.71)$.

Conclusions-Findings indicate that childhood trauma is an equally potent risk factor for early drinking onset for Black and White girls; the risk for early alcohol use in Black girls who have

\footnotetext{
${ }^{\dagger}$ Please address correspondence to Carolyn E. Sartor, Ph.D., Department of Psychiatry, Yale University School of Medicine, 389 Whitney Avenue, New Haven, CT, 06511, USA; carolyn.sartor@yale.edu.

Compliance with ethical standards

Ethical standards

This study has been approved by the appropriate ethics committee and has therefore been performed in accordance with the ethical standards laid down in the 1964 Declaration of Helsinki and its later amendments. For participants over age 18, informed consent was obtained and for participants under age 18, assent was obtained from participants and consent was obtained from the primary caregiver prior to participation in the study.

Conflicts of interest

On behalf of all authors, the corresponding author states that there is no conflict of interest.
} 
experienced traumatic events should not be underestimated. Results further indicate that low SES and neighborhood factors contribute to the associations of childhood trauma and race with alcohol use initiation.

\section{Keywords}

alcohol; childhood trauma; adolescent girls; African American; neighborhood disadvantage; socioeconomic status

\section{Introduction}

The evidence linking childhood trauma with risk for early initiation of alcohol use is compelling. In a recent study drawing data from the National Epidemiologic Survey on Alcohol and Related Conditions, Oberleitner et al. [1] reported that individuals who had experienced child maltreatment initiated alcohol use one year earlier on average than those without a history of child maltreatment. Similarly, in their large-scale investigation of substance use and childhood trauma - defined more broadly to also include adverse events such as witnessing violence - Dube and colleagues [2] found that the prevalence of alcohol use was higher in adolescents who had experienced adverse events and it increased with each additional adverse event. Although the association between childhood trauma and early alcohol use is well supported, it is not yet known if the magnitude of that association varies by race.

The possibility of racial differences in this link - between Black and White youth in particular - is suggested by the lower prevalence of alcohol use [3-6] and later initiation of use in Black youth [7-9] despite the higher prevalence of childhood trauma. Elevated prevalence of trauma exposure in Black vs. White children and adolescents have been observed for maltreatment [10] as well as community violence [11]. The paradoxical finding of greater childhood trauma exposure but lower prevalence of early drinking in Black youth suggests that the link between the two may differ for Black and White adolescents. A broader view of the environmental context of childhood trauma exposure and the development of drinking behaviors is needed to better understand their link and how it may differ for Black vs. White youth.

For a variety of complex reasons, a larger proportion of Black than White families live below the poverty line [12] and in single-parent households [13] and, reflecting historic limitations on educational opportunities, educational attainment is lower on average in Black vs. White adults [14]. Each of these indicators of low SES - low household income, singleparent-headed household, and low educational attainment - is associated with elevated risk for experiencing assaultive trauma $[15,16]$. Relatedly, Black families are more likely than White families to reside in disadvantaged urban neighborhoods [17], where the risk for experiencing assaultive trauma is greater than in more advantaged neighborhoods [11, $15,18]$. Notably, high levels of community cohesion have been found to buffer against risk for child maltreatment in low income neighborhoods [19,20]; thus, understanding neighborhood level influences on risk for trauma exposure requires consideration of neighborhood connectedness as well. 
Living in a single-parent-headed household is associated with elevated likelihood of early alcohol use initiation [21-23]. By contrast, other indicators of low SES have been linked to lower likelihood of adolescent alcohol use. For example, in Blum et al.'s study based on data from the National Longitudinal Study of Adolescent Health [21], higher family income levels were associated with greater frequency of alcohol use among $9^{\text {th }}$ to $12^{\text {th }}$ graders. Neighborhood factors have received less attention in the alcohol literature, but consistent with Blum et al.'s finding, Ennett and colleagues [24] reported that neighborhood attachment, which is generally higher in advantaged neighborhoods [25], was associated with higher prevalence of alcohol use among $5^{\text {th }}$ and $6^{\text {th }}$ graders. Given the overrepresentation of Black families in low-income communities, the reduced risk for early drinking associated with some indicators of low SES and neighborhood disadvantage may simply reflect the lower prevalence of alcohol use in Black vs. White youth. That is, in studies documenting racial differences in alcohol use, race may be at least in part a proxy for SES. Similarly, elevated prevalence of trauma exposure in Black youth may be a reflection of increased risk for trauma exposure in disadvantaged neighborhoods. Examining the relationship between childhood trauma and alcohol use in Black and White youth in the context of SES and neighborhood factors may allow us to disentangle these associations.

The current study examined alcohol use initiation in relation to childhood trauma in Black and White girls followed longitudinally from childhood through adolescence. We made use of an all-female sample because of its utility in identifying risk pathways that may be more common among girls, as suggested by the elevated prevalence of some forms of childhood trauma (e.g., sexual abuse) [26] and gender differences in timing of alcohol use onset [4,27]. We hypothesized that (1) the magnitude of association between childhood trauma and alcohol use initiation would be lower in Black than White girls and (2) indicators of low SES and neighborhood disadvantage would account for a significant degree of the association between childhood trauma and alcohol use. Furthermore, based on the assumption that witnessing violence would be more closely linked than interpersonal trauma (e.g., physical abuse, sexual assault) to living in disadvantaged neighborhoods, we also anticipated that low SES and neighborhood factors would account for the link between childhood trauma and alcohol use initiation to an even greater extent for childhood trauma defined more broadly to include events such as witnessing violence, compared to interpersonal trauma specifically. Building on recent work indicating that neighborhood disadvantage is associated with elevated risk for heavy drinking in Black adults but lower levels of alcohol use in White adults [28], we also explored potential differences by race in the association of low SES and neighborhood factors with alcohol use initiation.

\section{Materials and Methods}

\section{Participants}

The Pittsburgh Girls Study (PGS; N=2,450) is an urban community sample, oversampled for low-income neighborhoods, of four female age cohorts (ages 5-8 at wave 1). Girls and their primary caregivers were assessed annually via an accelerated longitudinal design. Details of PGS sample ascertainment have been reported in prior publications [29,30]. Briefly, participants were recruited in 1999-2000, with $85.2 \%$ of eligible families completing the 
first wave of data collection. PGS sample retention was high: $88.5 \%$ on average over the years that alcohol data used in the current analyses were collected (2003-2010), when girls were 11-17 years of age. As our interest is in differences between Black and White girls, the current study excluded the small subsample $(n=145)$ identified as other race (from primary caregiver's report of girl's race). We excluded an additional 238 cases that did not meet our criteria for the minimum range of assessment measures and years of coverage to capture trauma histories (described in method section), resulting in a final analytic sample of 2,068 girls (57.7\% Black, 42.3\% White). A larger proportion of White than Black participants were excluded ( $13.4 \%$ vs. $\left.7.9 \% ; \chi_{(1)}^{2}=18.13 ; p<0.001\right)$, reflecting the overall attrition pattern. Excluded participants were less likely than those included in analyses to endorse alcohol use $\left(11.5 \%\right.$ vs. $\left.44.5 \% ; \chi_{(1)}^{2}=43.88, p<0.001\right)$, reflecting their younger age at last assessment (13.4 vs. $\left.16.9 ; \mathrm{t}_{(103.41)}=15.98, \mathrm{p}<0.001\right)$.

\section{Procedure}

Written informed consent from the primary caregiver and verbal assent from the child were obtained prior to data collection. Face-to-face interviews were conducted annually in participants' homes, separately for the girl and her primary caregiver ( $94 \%$ mothers), by highly trained research staff. The protocol for maintaining confidentiality was explained to all participants, and the girls were reminded throughout the interview that their information would not be shared. The University of Pittsburgh's Human Research Protection Office approved the protocol. Respondents were compensated for study participation.

\section{Measures}

Age at alcohol use initiation-Past year alcohol use was assessed at each wave of data collection via the Nicotine, Alcohol, and Drug Substance Use measure [31], which queries frequency and usual quantity of consumption over the past year. There were 8 response options for frequency, starting with "I didn't within the past year," "less than 5 times in the past year," and "more than 5 times in the past year but less than once a month" and 7 response options for quantity, starting with "a sip or a taste," "less than one bottle/glass/ shot," and "1-2 bottles/glasses/shots." As we were interested in capturing use beyond a few sips, we created a proxy for age at first full drink: defined as the age at which respondents first reported consuming alcohol in any quantity 5 or more times in the past year, or the age at which respondents first reported consuming 1-2 drinks per occasion at any frequency in the past year.

Childhood trauma-History of childhood trauma was assessed with multiple measures in both child and primary caregiver interviews. Child reports were gathered with items from the Child PTSD Symptom Scale [32], the Abuse Questionnaire (developed by the PGS), and items pertaining to victimization from the Child Police Contact measure [33], which queried up to 4 different contacts per year. Additionally, girls who endorsed substance use were asked whether they had ever been victimized while under the influence of alcohol or drugs (using separate questions for alcohol and 8 different classes of drugs) and those who reported having a romantic partner were administered the Romantic Partner subscale of the Conflict Tactics Scale [34]. Primary caregiver reports of serious child victimization were 
gathered with the Health Questionnaire [33] and Child Police Contact measure [33]. Events queried and ages administered are shown by reporter for each measure in Table 1.

Interpersonal trauma was defined as being the victim of an attempted or actual physical attack, sexual assault, or abduction. The broader definition of childhood trauma included witnessing violence or involvement in a serious accident, in addition to interpersonal trauma. Endorsement of any qualifying event by either parent or child in a given year resulted in the coding of trauma as present in that year. Age at first exposure was calculated as the age at first endorsement of a qualifying event. Participants who endorsed a qualifying event at any age were categorized as positive for history of childhood trauma.

Range of measures and years assessed-To ensure that trauma history was well captured, only participants who met the following criteria were included in the study sample: (1) at least one report from a measure administered to primary caregivers; (2) at least one report from each of the three measures administered to all child participants (Child PTSD Symptom Scale, Abuse Questionnaire, and Child Police Contact); and (3) reports from at least one of three measures administered to all child participants for greater than half the 8year period (ages 10-17) during which they were administered, i.e. 5 or more years. Trauma data were available from a mean of $5.9(\mathrm{SD}=0.75)$ different measures (maximum possible $=7$ ). The mean number of years that reports from measures administered to all children were available was $7.7(\mathrm{SD}=0.70)$ (maximum possible=8).

Socioeconomic status (SES)—Socioeconomic status was indexed by primary caregiver's report of (1) single-parent household status ( $0=$ no, $1=y e s)$, (2) household receipt of public assistance $(0=$ no, $1=y e s)$, and (3) primary caregiver's highest level of education $(0=\geq 12$ years, $1=<12$ years $)$. Status on each indicator was derived from the primary caregiver's report in the first year that childhood trauma data were collected for a given participant (99.4\% in year of entry into the study; second year of participation for the remainder), thus reflecting SES at the onset of the risk period for trauma exposure captured in the study.

Neighborhood factors-Three neighborhood related domains were assessed. Consistent with the derivation of SES indicators, scores were drawn from the first year that childhood trauma data were collected for a given participant.

Low neighborhood safety was assessed with Your Neighborhood [33], a measure administered to primary caregivers, in which respondents rate 17 possible problems in their neighborhood (e.g., "delinquent gangs," "drug use and drug dealing in the open") on a 3point Likert scale (not a problem, somewhat of a problem, big problem). Ratings are summed, with higher scores reflecting lower degree of safety. Alphas ranged from 0.940.95 .

Community cohesion was assessed using the Community Survey [35], a 13-item measure administered to primary caregivers. Items (e.g., "I regularly stop and talk with people in my neighborhood," "I feel loyal to the people in my neighborhood") are rated on a 5-point 
Likert scale (strongly agree to strongly disagree) and summed, with higher scores reflecting higher degree of cohesion. Alphas ranged from 0.91-0.92.

Neighborhood physical disorder was indexed with 6 items from the Interviewer Impressions of the Neighborhood [36], a 25-question measure on which study interviewers record their observations of a range of neighborhood factors, primarily physical appearance of the neighborhood. Observations of graffiti, vacant buildings, abandoned cars, liquor bottles, cigarette butts, and other litter were dichotomously coded and summed, with higher scores reflecting a higher degree of disorder. Alphas ranged from 0.71-0.75.

\section{Data Analysis}

Associations between alcohol use initiation, childhood trauma, SES, and
neighborhood factors by race-Prevalence of alcohol use initiation, exposure to childhood trauma (i.e., ever experienced a traumatic event) indicators of low SES, age at first drink, and scores on neighborhood measures were calculated by race, with sample weights applied to mean and prevalence estimates to account for oversampling of families living in low-income neighborhoods. Tests for racial differences were conducted using binomial logistic regression analyses for dichotomous variables and independent sample t-tests for continuous variables. Univariate logistic regression analyses were also conducted to estimate associations of SES indicators and neighborhood factors with childhood trauma exposure and alcohol use initiation. Data sets were constructed and preliminary analyses conducted using SAS [37].

Childhood trauma as a predictor of alcohol use initiation-Cox proportional hazards $(\mathrm{PH})$ regression analyses were conducted to predict alcohol use initiation as a function of childhood trauma exposure, with interpersonal trauma and more broadly defined trauma examined in separate models, using Stata [38]. This survival analysis approach accounts for the possibility that participants who have not yet initiated alcohol use may do so in the future. It also involves testing the $\mathrm{PH}$ assumption that risk remains constant over time, using the Grambsch and Therneau test of the Schoenfeld residuals [39]. To ensure that only traumatic events preceding alcohol use initiation were treated as predictors, childhood trauma was modeled as time-varying. A "person-year" data set was created with each line of data representing a single year in the participant's life and childhood trauma was coded as absent in the years prior to its onset (based on calculated age at first exposure) and present from the year of first occurrence onward.

Analyses were conducted in two stages, including race, childhood trauma, and a race by childhood trauma interaction term in the first model. In the second step, dichotomously coded indicators of SES and continuous variables representing neighborhood factors were added and interaction terms representing race and childhood trauma by each of the SES and neighborhood variables were tested one at a time. Statistically significant interaction terms and all main effects were retained in the final models. 


\section{Results}

\section{Associations between alcohol use initiation, childhood trauma, SES, and neighborhood factors by race}

As seen in Table 2, prevalence and timing of alcohol use initiation differed significantly by race, with lower prevalence and slightly later onset of alcohol use in Black vs. White girls (37.7\% vs. 54.4\%; mean age of 15.29 vs. 15.04 years). A higher proportion of Black vs. White primary caregivers endorsed indicators of low SES. Prevalence of childhood trauma, under both definitions, was higher in Black girls (24.3\% vs. $15.5 \%$ for interpersonal and $29.0 \%$ vs. $17.5 \%$ for broadly defined childhood trauma). Neighborhood safety and cohesion were rated lower by primary caregivers and neighborhood physical disorder was rated higher by interviewers for neighborhoods where Black participants resided.

Results of logistic regression analyses testing for associations of SES and neighborhood factors with childhood trauma and alcohol use initiation are reported in Table 3. All indicators of low SES as well as neighborhood physical disorder were associated with lower odds of alcohol use initiation; neighborhood cohesion was associated with modestly elevated odds. All indicators of low SES, in addition to low neighborhood safety and neighborhood physical disorder, were associated with elevated odds - and neighborhood cohesion with a slightly lower odds - of childhood trauma exposure, both interpersonal and broadly defined.

\section{Childhood trauma as a predictor of alcohol use initiation}

Results of Cox PH regression analyses using interpersonal childhood trauma to predict alcohol use initiation are shown in the second and third columns of Table 4. No violations of $\mathrm{PH}$ assumptions were observed in either model. In Model 1, interpersonal childhood trauma was associated with elevated likelihood (hazard ratio $(\mathrm{HR})=1.70,95 \%$ confidence intervals (CI):1.44-2.01) and Black race with lower likelihood (HR=0.58, CI:0.51-0.66) of initiating alcohol use. There was no evidence for an interaction between race and childhood trauma. The addition of SES indicators and neighborhood factors in Model 2 resulted in a significant reduction in hazard ratios (i.e., point estimates were outside the bounds for the CIs in Model 1) for both childhood trauma (HR=1.36, CI:1.05-1.76) and race (HR=0.67, CI:0.55-0.81).

Null effects for receipt of public assistance, primary caregiver education level $<12$ years, and neighborhood factors were observed. Both a main effect (HR=1.27, CI:1.01-1.60) and an interaction with race were observed for single-paren-household status (HR=0.73, CI:0.540.99) (see Supplemental Figure 1), indicating that living in a single-parent household is associated with elevated likelihood of initiating alcohol use exclusively in White girls. We also found a significant interaction between childhood trauma and primary caregiver education level $<12$ years (HR=1.44, CI:1.02-2.03) (see Supplemental Figure 2), indicating that girls whose primary caregivers have less than a high school level of education have an even greater likelihood of initiating alcohol use when exposed to childhood trauma.

Results of Cox PH regression analyses using broadly defined childhood trauma to predict alcohol use initiation are shown in columns 4 and 5 of Table 4 . Results were highly consistent with those from the interpersonal childhood trauma analyses. Hazard ratios in both Model 1 and Model 2 were nearly identical to those from the childhood interpersonal 
trauma models and no violations of the PH assumption were observed. (The childhood trauma by primary caregiver education level interaction is depicted in Supplemental Figure 3.)

\section{Discussion}

Building on the paradoxical findings of greater exposure to trauma but lower prevalence of alcohol use in Black vs. White youth, we assessed for racial differences in the association between childhood trauma and alcohol use initiation in Black and White girls, considering socioeconomic and neighborhood factors that vary by race and are linked to both trauma exposure and alcohol use. Consistent with the existing literature, prevalence of both childhood interpersonal trauma and more broadly defined childhood trauma were higher in Black than White girls [10,11] and alcohol use initiation was less prevalent [3-6], with slightly older age at onset in Black girls [7-9]. Associations between childhood trauma (under both definitions) and alcohol use were observed, as expected [1,2]. However, we did not find evidence that the magnitude of association differed by race; interactions between race and childhood trauma were non-significant. We hypothesized a lower degree of association between childhood trauma and alcohol use in Black vs. White girls as the most straightforward explanation for the counterintuitive elevated rate of trauma exposure but lower likelihood of alcohol use initiation in Black compared to White youth. Given the wide range of risk and protective factors that influence alcohol use - genetic, psychiatric, peer, family, cultural, and community level - it may simply be that this particular risk pathway to early alcohol use is equally strong in Black and White girls and the differences in prevalence and timing of alcohol use are attributable to variations in other pathways that were not examined in the current study. Peer influences [40] may be one such example, as Black youth are less likely than White youth to report alcohol consumption by close friends [41].

\section{SES, neighborhood factors and the link between childhood trauma and alcohol use initiation}

Individually, only one of the indicators of SES and neighborhood factors (single-parent household status) examined in our study was significantly associated with liability to alcohol use initiation and in only one of the models. However, inclusion of the set of indicators in analyses resulted in statistically significant changes in the hazard ratios for race and childhood trauma in both models, meaning that SES and neighborhood factors accounted in part for racial differences in liability to initiation as well as a significant proportion of the association between childhood trauma and alcohol use initiation.

The increase in hazard ratio for Black race following the addition of SES and neighborhood variables indicates that race is in part a marker for low SES and neighborhood factors in the current sample. That is, the lower likelihood of initiating alcohol use in Black vs. White girls is partially attributable to the disproportionate number of Black youth living in low-income households, which has been associated with lower frequency of adolescent alcohol use [21]. The reduction in hazard ratio for childhood trauma similarly indicates that a substantial proportion of the variance in liability to alcohol use initiation attributed to childhood trauma exposure can be accounted for by socioeconomic disadvantage, which has consistently been 
tied to elevated risk for experiencing trauma during childhood $[15,16]$. Our hypothesis that childhood trauma that encompasses non-interpersonal events, most notably, witnessing violence, would be more strongly related to SES and neighborhood factors than interpersonal trauma was not supported. We based the hypothesis on the assumption that interpersonal trauma would be less directly related to living in disadvantaged neighborhoods, but descriptions of interpersonal traumatic events experienced by study participants indicated that assaultive events were by no means limited to child maltreatment; a substantial number occurred outside the home, e.g., in the neighborhood or at a friend's home.

A secondary aim of the study was to explore possible differences by race in the contribution of low SES and neighborhood factors to the association between childhood trauma and alcohol use. However, we did not find support for stratifying analyses by race - from either unadjusted models or models adjusted for SES indicators and neighborhood factors that are frequently imbalanced across race. As a result, we did not produce separate models for Black and White participants and therefore could not directly compare across racial groups the change in the estimated likelihood of alcohol use initiation conferred by childhood trauma after adjusting for all SES and neighborhood factors in combination. However, by testing for interactions of individual indicators of SES and neighborhood factors with both race and childhood trauma in the full sample, we identified some differences by race and history of childhood trauma in the association of certain indicators of SES with alcohol use initiation.

In both the interpersonal and broadly defined childhood trauma models, we observed a significant interaction between race and single-parent-household status, indicating that residing in a single-parent household was associated with elevated likelihood of initiating alcohol use exclusively in White girls. Of the three indicators of low SES examined in the current study, living in a single-parent household is the only one that has consistently been linked to elevated risk for early alcohol use [22,23]. In fact, in Blum et al.'s study based on National Longitudinal Study of Adolescent Health data [21], adolescents residing with a single parent reported a higher frequency of alcohol use than those residing with two parents, but frequency of alcohol use was actually lower among adolescents from lowincome families. It appears then that living in a single-parent household represents more than simply economic disadvantage and, importantly, does not carry the same degree of risk for alcohol use initiation for Black girls as it does for White girls. Consistent with trends in the general population [13], living with a single parent was much more common for Black than White girls in the current study (57.6\% vs. $18.6 \%)$. As a more normative household structure, it is possible that there is better parenting support in place (e.g., involvement of extended family) for single parents in Black families, and thus lower associated liability to alcohol use in Black vs. White youth.

The other interaction observed in both childhood trauma models was between childhood trauma and primary caregiver education level, such that liability to alcohol use initiation conferred by trauma exposure was greater in girls whose primary caregivers had less than a high school level of education. As in the case of single-parent-household status, primary caregiver education level is an indicator of economic advantage but may capture other 
aspects of family environment and parental attitudes as well, so possible interpretations of this finding should include explanations other than those directly related to household income level, e.g., affordability of mental health care. For example, perceptions that mental health professionals may not appreciate the additional stressors experienced by individuals in low-income communities or the lower likelihood that signs of trauma would be detected by teachers or school counselors in schools with more limited resources may also impede seeking help that could reduce risk for alcohol use following traumatic events.

\section{Limitations}

Despite its strengths, the current study has certain limitations. First, although we made use of a range of trauma measures, collected information on trauma history from primary caregivers as well as girls, and applied stringent standards regarding missing trauma data, any missing data could lead to miscategorizing a trauma-exposed participant as unexposed, which could result in underestimating associations of childhood trauma with SES, neighborhood factors, or alcohol use. Second, the availability of trauma reports exclusively from primary caregivers prior to age 10 likely resulted in underreporting of traumatic experiences in early childhood. Third, many of the questions in the trauma assessments were not event-specific (e.g., emergency room visits related to "gunshot, stabbing, sexual assault, or rape") so we cannot draw inferences about the association of specific types of traumatic events with alcohol use initiation, SES, or neighborhood factors. Fourth, although the inclusion of trauma related questions in different sections of the interview increased the likelihood of accurately identifying trauma-exposed participants, this method did not allow us to get a count of the number of events experienced, as it would be possible to endorse items in different sections of the interview in reference to the same event. Finally, the sample was ascertained from an urban population, with low-income neighborhoods oversampled by design, so findings may not generalize to Black and White girls in non-urban or higher income populations.

\section{Conclusions and future directions}

Although adolescent alcohol use is less common in Black than White girls - despite the higher prevalence of childhood trauma in Black girls - we need to be careful not to underestimate risk for alcohol use initiation in Black youth who have experienced traumatic events. Our findings indicate that childhood trauma is an equally potent risk factor for adolescent drinking onset for Black girls as for White girls. We further found that associations of both Black race and childhood trauma with alcohol use initiation can be explained in part by SES and neighborhood factors and that the relevance of certain SES indicators (i.e., primary caregiver education level and residing in a single-parent household) to liability to alcohol use initiation differ by race and history of childhood trauma. In addition to exploring the generalizability of our findings to other substances as well as males and members of other racial groups, it is critical that efforts aimed at identifying distinctions between Black and White youth in other pathways to early alcohol use continue, toward the end of refining etiological models of alcohol use in Black youth. 


\section{Supplementary Material}

Refer to Web version on PubMed Central for supplementary material.

\section{Acknowledgments}

This work was supported by grants from the National Institute on Alcohol Abuse and Alcoholism (AA023549, AA007453, and AA017921), the National Institute on Drug Abuse (DA012237), the National Institute on Mental Health (MH056630), FISA Foundation, and Falk Foundation. We thank all of the research participants and their families for the time they dedicated to this study.

\section{References}

1. Oberleitner LM, Smith PH, Weinberger AH, Mazure CM, McKee SA. Impact of exposure to childhood maltreatment on transitions to alcohol dependence in women and men. Child Maltreat. 2015; 20:301-308. [PubMed: 26130105]

2. Dube SR, Miller JW, Brown DW, Giles WH, Felitti VJ, Dong M, Anda RF. Adverse childhood experiences and the association with ever using alcohol and initiating alcohol use during adolescence. J Adolesc Health. 2006; 38:444e1-444e10. [PubMed: 16549308]

3. Dauber S, Hogue A, Paulson JF, Leiferman JA. Typologies of alcohol use in White and African American adolescent girls. Subst Use Misuse. 2009; 44:1121-1141. [PubMed: 19544150]

4. Jackson KM, Sher KJ, Cooper ML, Wood PK. Adolescent alcohol and tobacco use: onset, persistence and trajectories of use across two samples. Addiction. 2002; 97:517-531. [PubMed: 12033653]

5. Johnston, LD., O'Malley, PM., Miech, RA., Bachman, JG., Schulenberg, JE. Monitoring the Future: national survey results on drug use, 1975-2016: Overview, key findings on adolescent drug use. The University of Michigan; Ann Arbor, MI: 2017.

6. Wallace JM Jr, Brown TN, Bachman JG, LaVeist TA. The influence of race and religion on abstinence from alcohol, cigarettes and marijuana among adolescents. J Stud Alcohol. 2003; 64:843-848. [PubMed: 14743948]

7. Jackson KM. Progression through early drinking milestones in an adolescent treatment sample. Addiction. 2010; 105:438-449. [PubMed: 20402987]

8. Malone PS, Northrup TF, Masyn KE, Lamis DA, Lamont AE. Initiation and persistence of alcohol use in United States: Black, Hispanic, and White male and female youth. Addict Behav. 2012; 37:299-305. [PubMed: 22136874]

9. Sartor CE, Jackson KM, McCutcheon VV, Duncan AE, Grant JD, Werner KB, Bucholz KK. Progression from first drink, first intoxication, and regular drinking to alcohol use disorder: a comparison of African American and European American youth. Alcohol Clin Exp Res. 2016; 40:1515-1523. [PubMed: 27256613]

10. Wildeman C, Emanuel N, Leventhal JM, Putnam-Hornstein E, Waldfogel J, Lee H. The prevalence of confirmed maltreatment among US children, 2004 to 2011. JAMA Pediatr. 2014; 168:706-713. [PubMed: 24887073]

11. Gibson CL, Morris SZ, Beaver KM. Secondary exposure to violence during childhood and adolescence: does neighborhood context matter? Justice Q. 2009; 26:30-57.

12. Macartney, S., Bishaw, A. American Community Survey Briefs. Washington, DC: US Census Bureau; 2013. Poverty rates for selected detailed race and Hispanic groups by state and place: 2007-2011.

13. Vespa, J., Lewis, JM., Kreider, RM. America's families and living arrangements: 2012. Washington, DC: US Census Bureau; 2013.

14. Ryan, CL., Bauman, K. Current Population Reports. Washington, DC: US Census Bureau; 2016. Educational attainment in the United States: 2015.

15. Breslau N, Kessler RC, Chilcoat HD, Schultz LR, Davis GC, Andreski P. Trauma and posttraumatic stress disorder in the community: the 1996 Detroit Area Survey of Trauma. Arch Gen Psychiatry. 1998; 55:626-632. [PubMed: 9672053] 
16. Turner HA, Finkelhor D, Ormrod R. Family structure variations in patterns and predictors of child victimization. Am J Orthopsychiat. 2007; 77:282-295. [PubMed: 17535126]

17. Peterson RD, Krivo LJ. Macrostructural analyses of race, ethnicity, and violent crime: Recent lessons and new directions for research. Annu Rev Sociol. 2005; 31:331-356.

18. Boyle DJ, Hassett-Walker C. Individual-level and socio-structural characteristics of violence: an emergency department study. J Interpers Violence. 2008; 23:1011-1026. [PubMed: 18296572]

19. Ernst JS. Community-level factors and child maltreatment in a suburban community. Soc Work Res. 2001; 25:133-142.

20. Korbin JE, Coulton CJ, Chard S, Platt-Houston C, Su M. Impoverishment and child maltreatment in African American and European American neighborhoods. Dev Psychopathol. 1998; 10:215232. [PubMed: 9635222]

21. Blum RW, Beuhring T, Shew ML, Bearinger LH, Sieving RE, Resnick MD. The effects of race/ ethnicity, income, and family structure on adolescent risk behaviors. Am J Public Health. 2000; 90:1879-1884. [PubMed: 11111260]

22. Donovan JE, Molina BS. Childhood risk factors for early-onset drinking. J Stud Alcohol Drugs. 2011; 72:741-751. [PubMed: 21906502]

23. Dooley D, Prause J, Ham-Rowbottom KA, Emptage N. Age of alcohol drinking onset: precursors and the mediation of alcohol disorder. J Child Adoles Subst. 2005; 15:19-37.

24. Ennett ST, Flewelling RL, Lindrooth RC, Norton EC. School and neighborhood characteristics associated with school rates of alcohol, cigarette, and marijuana use. J Health Soc Behav. 1997; 38:55-71. [PubMed: 9097508]

25. Geis KJ, Ross CE. A new look at urban alienation: the effect of neighborhood disorder on perceived powerlessness. Soc Psychol Quart. 1998; 61:232-246.

26. Dube SR, Felitti VJ, Dong M, Giles WH, Anda RF. The impact of adverse childhood experiences on health problems: evidence from four birth cohorts dating back to 1900. Prev Med. 2003; 37:268-277. [PubMed: 12914833]

27. York JL, Welte J, Hirsch J, Hoffman JH, Barnes G. Association of age at first drink with current alcohol drinking variables in a national general population sample. Alcohol Clin Exp Res. 2004; 28:1379-1387. [PubMed: 15365309]

28. Karriker-Jaffee KJ, Zemore SE, Mulia N, Jones-Webb R, Bond J, Greenfield TK. Neighborhood disadvantage and adult alcohol outcomes: differential risk by race and gender. J Stud Alcohol Drugs. 2012; 73:865-873. [PubMed: 23036203]

29. Hipwell AE, Loeber R, Stouthamer-Loeber M, Keenan K, White HR, Kroneman L. Characteristics of girls with early onset disruptive and antisocial behaviour. Crim Behav Ment Health. 2002; 12:99-118. [PubMed: 12357260]

30. Keenan K, Hipwell A, Chung T, Stepp S, Stouthamer-Loeber M, Loeber R, McTigue K. The Pittsburgh Girls Study: overview and initial findings. J Clin Child Adolesc Psychol. 2010; 39:506521. [PubMed: 20589562]

31. Pandina RJ, Labouvie EW, White HR. Potential contributions of the life-span developmental approach to the study of adolescent alcohol and drug use: the Rutgers Health and Human Development Project, a working model. J Drug Issues. 1984; 14:253-268.

32. Foa EB, Johnson KM, Feeny NC, Treadwell KRH. The Child PTSD Symptom Scale: A preliminary examination of its psychometric properties. J Clin Child Psychol. 2001; 30:376-384. [PubMed: 11501254]

33. Loeber, R., Farrington, D., Stouthamer-Loeber, M., Van Kammen, W. Antisocial behavior and mental health problems: explanatory factors in childhood and adolescence. Lawrence Erlbaum Associates; Mahwah, NJ: 1998.

34. Straus MA, Hamby SL, Boney-McCoy S, Sugarman DB. The revised Conflict Tactics Scales (CTS2): development and preliminary psychometric data. J Fam Issues. 1996; 17:283-316.

35. Gorman-Smith D, Tolan PH, Henry D. A developmental-ecological model of the relation of family functioning to patterns of delinquency. J Quant Criminol. 2000; 16:169-198.

36. Wei E, Hipwell A, Pardini D, Beyers JM, Loeber R. Block observations of neighbourhood physical disorder are associated with neighbourhood crime, firearm injuries and deaths, and teen births. $\mathbf{J}$ Epidemiol Commun H. 2005; 59:904-908. 
37. SAS Institute. SAS version 9.4. Cary, NC: 2013.

38. StataCorp. Stata version 9.2. College Station, TX: 2007.

39. Grambsch P, Therneau TM. Proportional hazards tests and diagnostics based on weighted residuals. Biometrika. 1994; 81:515-526.

40. Leung RK, Toumbourou JW, Hemphill SA. The effect of peer influence and selection processes on adolescent alcohol use: a systematic review of longitudinal studies. Health Psychol Rev. 2014; 8:426-457. [PubMed: 25211209]

41. Duncan SC, Strycker LA, Duncay TE. Alcohol use of African Americans and Whites From Ages 9-20: descriptive results from a longitudinal study. J Ethn Subst Abuse. 2012; 11:214-225.

[PubMed: 22931156] 
Table 1

Measures administered to assess exposure to traumatic events during childhood

\begin{tabular}{|c|c|c|c|}
\hline Measure & Traumatic event(s) & Items used & Ages administered \\
\hline \multicolumn{4}{|l|}{ Child report } \\
\hline $\begin{array}{l}\text { Child PTSD Symptom } \\
\text { Scale }\end{array}$ & $\begin{array}{l}\text { Physical abuse/assault; } \\
\text { sexual abuse/assault; } \\
\text { abduction; witnessing } \\
\text { violence; serious accident }\end{array}$ & $\begin{array}{l}\text { Description of event if responded "yes" to "In the past year, } \\
\text { has anything happened to you that was really terrifying } \\
\text { (scary) for you?" }\end{array}$ & $10-17$ \\
\hline Abuse Questionnaire & Sexual abuse & $\begin{array}{l}\text { (1) "Has someone touched your private parts in a way you } \\
\text { didn't want them to or in a way that made you } \\
\text { uncomfortable?" } \\
\text { (2) "Has someone made you touch their body's private parts } \\
\text { when you didn't want to?" }\end{array}$ & $12-17$ \\
\hline $\begin{array}{l}\text { Victimization Under the } \\
\text { Influence of Alcohol or } \\
\text { Drugs }\end{array}$ & $\begin{array}{l}\text { Physical assault; sexual } \\
\text { assault }\end{array}$ & $\begin{array}{l}\text { "How often in the past year, have you been victimized when } \\
\text { drinking or drunk/using or high on [drug] \& for example, } \\
\text { mugged or forced to have sex (raped)?" } \\
\text { (Queried separately for alcohol \& } 8 \text { classes of drugs) }\end{array}$ & $12-17$ \\
\hline Child Police Contact & $\begin{array}{l}\text { Physical assault; sexual } \\
\text { assault }\end{array}$ & $\begin{array}{l}\text { If reported being victim of a crime in the past year, "Tell me } \\
\text { what crime you were a victim of." shooting, including drive- } \\
\text { by; aggravated assault; other assault; forcible rape; statutory } \\
\text { rape; other sex offenses; child abuse/neglect (up to } 4 \text { events } \\
\text { queried per year) }\end{array}$ & $14-17$ \\
\hline $\begin{array}{l}\text { Conflict Tactics Scale - } \\
\text { Romantic Partner }\end{array}$ & Sexual assault & $\begin{array}{l}\text { Partner used force for sex } \\
\text { (Oral or anal queried separately from sexual intercourse) }\end{array}$ & $16-17$ \\
\hline \multicolumn{4}{|l|}{ Primary caregiver report } \\
\hline Child Police Contact & $\begin{array}{l}\text { Physical abuse/assault; } \\
\text { sexual abuse/assault; } \\
\text { neglect }\end{array}$ & $\begin{array}{l}\text { If reported that child was victim of a crime in the past year, } \\
\text { "What crime she has been a victim of?" shooting, including } \\
\text { drive-by; aggravated assault; other assault; forcible rape; } \\
\text { statutory rape; other sex offenses; child abuse/neglect (up to } \\
4 \text { events queried per year) }\end{array}$ & $5-17$ \\
\hline Health Questionnaire & $\begin{array}{l}\text { Physical abuse/assault; } \\
\text { sexual abuse/assault }\end{array}$ & $\begin{array}{l}\text { If reported } 1 \text { or more emergency room visits in the past year, } \\
\text { "Did she go to the ER because she was a victim of violence } \\
\text { (gunshot, stabbing, sexual assault, rape)?" }\end{array}$ & $10-17$ \\
\hline
\end{tabular}

Source of data for both interpersonal and non-interpersonal traumatic events 
Table 2

Alcohol use initiation ${ }^{a}$, childhood trauma exposure, socioeconomic status (SES), and neighborhood factors by race $^{b}$

\begin{tabular}{|c|c|c|c|c|}
\hline & & Black girls & White girls & Test statistic \\
\hline \multicolumn{5}{|l|}{ Alcohol use initiation } \\
\hline \multicolumn{2}{|l|}{ Prevalence * } & $37.7 \%$ & $54.4 \%$ & $\begin{array}{l}\text { OR }=0.50 \\
\text { (CI: } 0.42-0.60)\end{array}$ \\
\hline \multicolumn{2}{|l|}{ Age at initiation: mean $(\mathrm{SD}) *$} & $15.29(1.51)$ & $15.04(1.86)$ & $\mathrm{t}_{(916.9)}=2.29 ; p=0.02$ \\
\hline \multicolumn{5}{|l|}{ Childhood trauma exposure } \\
\hline \multicolumn{5}{|l|}{ Interpersonal } \\
\hline \multicolumn{2}{|l|}{ Lifetime prevalence ${ }^{*}$} & $24.3 \%$ & $15.5 \%$ & $\begin{array}{l}\mathrm{OR}=1.77 \\
\text { (CI: } 1.41-2.21)\end{array}$ \\
\hline \multicolumn{2}{|l|}{ Age at $1^{\text {st }}$ experience: mean (SD) } & $13.49(2.65)$ & $12.92(3.43)$ & $\mathrm{t}_{(248.0)}=1.77 ; p=0.08$ \\
\hline \multirow{4}{*}{ Years experienced $1+$ events $c$} & 1 & $70.3 \%$ & $77.9 \%$ & \multirow{4}{*}{$\chi_{(3)}^{2}=2.83 ; p=0.42$} \\
\hline & 2 & $19.8 \%$ & $15.4 \%$ & \\
\hline & 3 & $8.9 \%$ & $5.9 \%$ & \\
\hline & 4 & $1.0 \%$ & $0.8 \%$ & \\
\hline \multicolumn{5}{|l|}{ Broadly defined } \\
\hline \multicolumn{2}{|l|}{ Lifetime prevalence * } & $29.0 \%$ & $17.5 \%$ & $\begin{array}{l}\mathrm{OR}=1.95 \\
\text { (CI: } 1.57-2.41)\end{array}$ \\
\hline \multicolumn{2}{|l|}{ Age at $1^{\text {st }}$ experience: mean (SD) } & $13.16(2.63)$ & $13.04(3.40)$ & $\mathrm{t}_{(275.5)}=0.41 ; p=0.68$ \\
\hline \multirow[t]{4}{*}{ Years experienced $1+$ events $c^{*}$} & 1 & $66.1 \%$ & $77.9 \%$ & \multirow{4}{*}{$\chi_{(3)}^{2}=8.06 ; p=0.04$} \\
\hline & 2 & $23.9 \%$ & $16.2 \%$ & \\
\hline & 3 & $8.3 \%$ & $3.9 \%$ & \\
\hline & 4 & $1.7 \%$ & $2.0 \%$ & \\
\hline \multicolumn{5}{|l|}{ Indicators of SES } \\
\hline \multicolumn{2}{|l|}{ Single-parent household * } & $57.6 \%$ & $18.6 \%$ & $\begin{array}{l}\text { OR=6.22 } \\
\text { (CI: } 5.07-7.64)\end{array}$ \\
\hline \multicolumn{2}{|l|}{ Receipt of public assistance * } & $53.0 \%$ & $18.7 \%$ & $\begin{array}{l}\mathrm{OR}=5.28 \\
\text { (CI: } 4.31-6.48)\end{array}$ \\
\hline \multicolumn{2}{|c|}{ Primary caregiver education $<12$ years $*$} & $53.0 \%$ & $38.6 \%$ & $\begin{array}{l}\mathrm{OR}=1.95 \\
\text { (CI: } 1.63-2.32)\end{array}$ \\
\hline \multicolumn{5}{|l|}{ Neighborhood factors } \\
\hline \multicolumn{2}{|l|}{ Low safety: mean $(\mathrm{SD}) *$} & $24.56(7.11)$ & $20.40(5.72)$ & $\mathrm{t}_{(2043.5)}=14.52 ; p<0.01$ \\
\hline \multicolumn{2}{|l|}{ Cohesion: mean (SD) ${ }^{*}$} & $31.38(7.85)$ & $38.66(8.15)$ & $\mathrm{t}_{(2062)}=20.59 ; p<0.01$ \\
\hline \multicolumn{2}{|l|}{ Physical disorder: mean (SD) * } & $1.78(1.30)$ & $0.81(1.19)$ & $\mathrm{t}_{(1951.6)}=17.02 ; p<0.01$ \\
\hline
\end{tabular}

$\mathrm{OR}=$ odds ratio; $\mathrm{CI}=95 \%$ confidence intervals; Black relative to White girls;

*

$\mathrm{p}<0.05$;

${ }^{a}$ ever consumed a full alcoholic drink (based on proxy for age at first drink);

$b$

prevalence and means adjusted for sampling design 
$c$ among girls with a history of trauma exposure 
Table 3

Associations of alcohol use initiation ${ }^{a}$ and childhood trauma exposure with indicators of socioeconomic status (SES) and neighborhood factors

\begin{tabular}{|c|c|c|c|}
\hline & \multicolumn{3}{|c|}{ Odds Ratio (95\% Confidence Intervals) } \\
\hline & Alcohol use initiation & Interpersonal childhood trauma & Broadly defined childhood trauma \\
\hline \multicolumn{4}{|l|}{ Indicators of SES } \\
\hline Single-parent household & $0.76(0.64-0.91)^{*}$ & $1.40(1.13-1.73)^{*}$ & $1.47(1.20-1.80)^{*}$ \\
\hline Receipt of public assistance & $0.73(0.61-0.87)^{*}$ & $1.54(1.24-1.90)^{*}$ & $1.57(1.29-1.93)^{*}$ \\
\hline Primary caregiver education $<12$ years & $0.80(0.67-0.95)^{*}$ & $1.51(1.22-1.87)^{*}$ & $1.54(1.26-1.89)^{*}$ \\
\hline \multicolumn{4}{|l|}{ Neighborhood factors } \\
\hline Low safety & $0.99(0.98-1.00)$ & $1.02(1.01-1.04)^{*}$ & $1.02(1.01-1.04)^{*}$ \\
\hline Cohesion & $1.02(1.01-1.03)^{*}$ & $0.98(0.97-0.99)^{*}$ & $0.98(0.97-0.99)^{*}$ \\
\hline Physical disorder & $0.88(0.83-0.94)^{*}$ & $1.12(1.04-1.21)^{*}$ & $1.13(1.05-1.21)^{*}$ \\
\hline
\end{tabular}

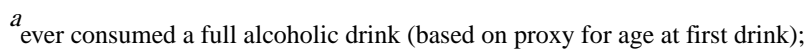

* $p<0.05$ 


\section{Table 4}

Results of Cox proportional hazards regression analyses predicting alcohol use initiation ${ }^{a}$ as a function of childhood trauma exposure

\begin{tabular}{|c|c|c|c|c|}
\hline & \multicolumn{4}{|c|}{ Hazards Ratio (95\% Confidence Intervals) } \\
\hline & \multicolumn{2}{|c|}{ Interpersonal childhood trauma } & \multicolumn{2}{|c|}{ Broadly defined childhood trauma } \\
\hline Childhood trauma & $1.70(1.44-2.01)^{*}$ & $1.36(1.05-1.76)^{*}$ & $1.70(1.46-1.99)^{*}$ & $1.34(1.05-1.71)^{*}$ \\
\hline \multicolumn{5}{|l|}{ Indicators of SES } \\
\hline Single-parent household & ------- & $1.27(1.01-1.60)^{*}$ & ------- & $1.27(1.00-1.60)$ \\
\hline Receipt of public assistance & --------- & $0.97(0.83-1.13)$ & ---------- & $0.97(0.83-1.14)$ \\
\hline Cohesion & --------- & $1.00(0.99-1.01)$ & ---------- & $1.00(0.99-1.01)$ \\
\hline Physical disorder & ---------- & $0.97(0.92-1.03)$ & ---------- & $0.98(0.92-1.03)$ \\
\hline Black race $\mathrm{x}$ single-parent household & ---------- & $0.73(0.54-0.99) *$ & ---------- & $0.73(0.54-0.99)^{*}$ \\
\hline Trauma $\mathrm{x}$ primary caregiver education $<12$ years & --------- & $1.44(1.02-2.03)^{*}$ & --------- & $1.48(1.07-2.05)^{*}$ \\
\hline
\end{tabular}

